\title{
Cosmesis in patients with breast neoplasia submitted to the hypofractionated radiotherapy with of intensity-modulated beam
}

Fabiana Accioli Miranda

Marina Tamm Lannes Vieira ${ }^{2}$

Fabio Ynoe de Moraes $^{3}$

Gustavo Nader Marta ${ }^{4}$

Heloísa de Andrade Carvalho ${ }^{5}$

Samir Abdallah Hanna ${ }^{6}$

\begin{abstract}
1. Radioteraphy of Hospital Sírio-Libanês - SP, São Paulo (SP), Brasil. 2. Radiation Oncologist of COI (Clínicas Oncológicas Integradas - RI), Rio de laneiro (RJ), Brasil. 3. Radiation Medicine Program, Princess Margaret Hospital University of Toronto, Toronto, Ontario, Canada. 4. Radiation Oncologist of Hospital Sírio-Libanês - SP and Instituto do Câncer do Estado de São Paulo, São Paulo (SP), Brasil. 5. Radiation Oncologist of Hospital Sírio-Libanês - SP and Instituto de Radiologia (InRad) - SP, São Paulo (SP), Brasil.

6. Radiation Oncologist of Hospital Sírio-Libanês - SP, São Paulo (SP), Brasil.
\end{abstract}

http://dx.doi.org/10.1590/1806-9282.64.11.1023

\section{SUMMARY}

OBJECTIVE: To assess the cosmetic satisfaction of patients diagnosed with breast cancer submitted to the hypofractionated radiotherapy with IMRT (hIMRT) technique and its correlation with dosimetric data of the radiotherapy planning.

MATERIALS AND METHODS: The retrospective cohort study that assessed women with a diagnosis of malignant breast neoplasia submitted to the conservative treatment or radical mastectomy and treated with hIMRT. In the period between August 2007 to December 2014, in a philanthropic / private institution, 170 records were selected. The cosmetic assessment was carried out by means of the Harvard/RTOG/NSABP scale with one-year minimum range after treatment. The collected dosimetric data were: breast / chest wall volume, volume that received 95\% (V95\%) and 107\% (V107\%) of the prescribed dose.

RESULTS: The volume of the treated breasts ranged from 169 to $2.103 \mathrm{ml}$ (median = 702; IQR: 535 to $914 \mathrm{ml}$ ). Median V95\% was $86.7 \%$ (54.6-96.6\%; IQR: 80.0\% to 90.6\%); eight (5.7\%) patients had V95\% higher than 95\%. Median V107\% was 0\% (0\%-16.3\%; IQR: 0.0\% to $0.3 \%$ and 13$) ; 9.3 \%$ patients had V107\% higher than $2 \%$. One hundred and thirty-three (78.2\%) patients responded to the cosmetic assessment: 99 (74.4\%) considered the cosmetic results excellent. Significant associations between cosmetic assessment and breast volume ( $p=0.875)$, V95\% ( $p=0.294)$ e V107\% ( $p=0.301)$ were not found.

CONCLUSION: The cosmetic results showed favorable when using hIMRT, and the lack of correlation with usual the dosimetric data illustrates the capacity of hIMRT to minimize the heterogeneity of the dose in this endpoint, even in voluminous breasts.

KEYWORDS: Hypofractionation. Breast neoplasia. Radiotherapy.

\section{INTRODUCTION}

The breast cancer is a malignant neoplasia more commonly in women. It is known that radiotherapy (RT) is an integral part of the adjuvant treatment for the most patients, regardless of the type of surgery that is carried out, producing benefits in local control and survival'.

Significant breakthroughs were made in RT, including modernization of imaging techniques, equip-

DATE OF SUBMISSION: 28-May-2018

DATE OF ACCEPTANCE: 05-Aug-2018

Corresponding Author: Fabiana A. Miranda

Radioteraphy of Hospital Sírio-Libanês

Rua Adma Jafet, 91, São Paulo, SP, Brasil - CEP 01308-050

E-mail: fabimiranda10@hotmail.com, fabiana.amiranda@hsl.org.br 
ment, and planning systems, allowing better accuracy in defining the target volume of treatment and more conformal plannings ${ }^{2}$. The latest techniques of treatment, including conformal three-dimensional RT (RT3DC) and intensity modulated RT (IMRT), allow a greater preservation of adjuvant bodies ${ }^{3,4}$.

Field-in-field technique may be carried out with opposed tangential fields and it is considered a simple way of IMRT (forward-planned IMRT), without the need for a reverse planning system or other more complex technologies. Smaller fields are added to the main field in order to achieve a homogenization of the dose by handling the collimator blades. This technique may be easily implanted and the treatment period is similar to the conventional techniques ${ }^{5,6}$ (Figure 1).

The conventional treatments use profiles from five to six weeks of duration, total dose of $50 \mathrm{~Gy}$. Therefore, for patients selected, the hypofractionated regimes (shorter period of treatment with a higher dose per fraction), such as 42.5 Gy in 16 fractions or $40 \mathrm{~Gy}$ in 15 fractions are equally efficient, besides

\section{FIGURE 1: FIELD-IN-FIELD TECHNIQUE X 3D}

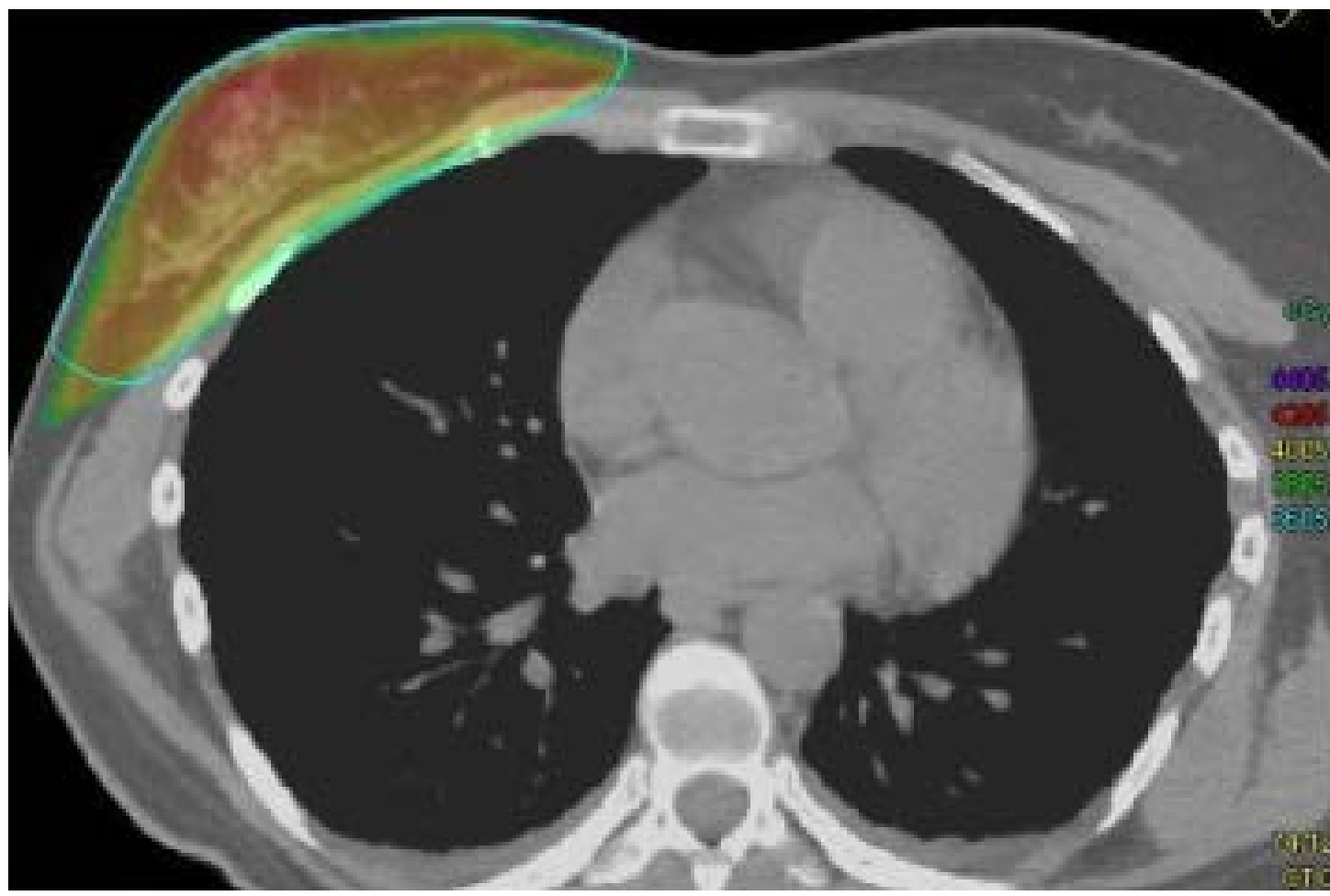

Field-in-field technique Defined as the standard modality of IMRT for breast cancer with a homogeneous distribution of doses.
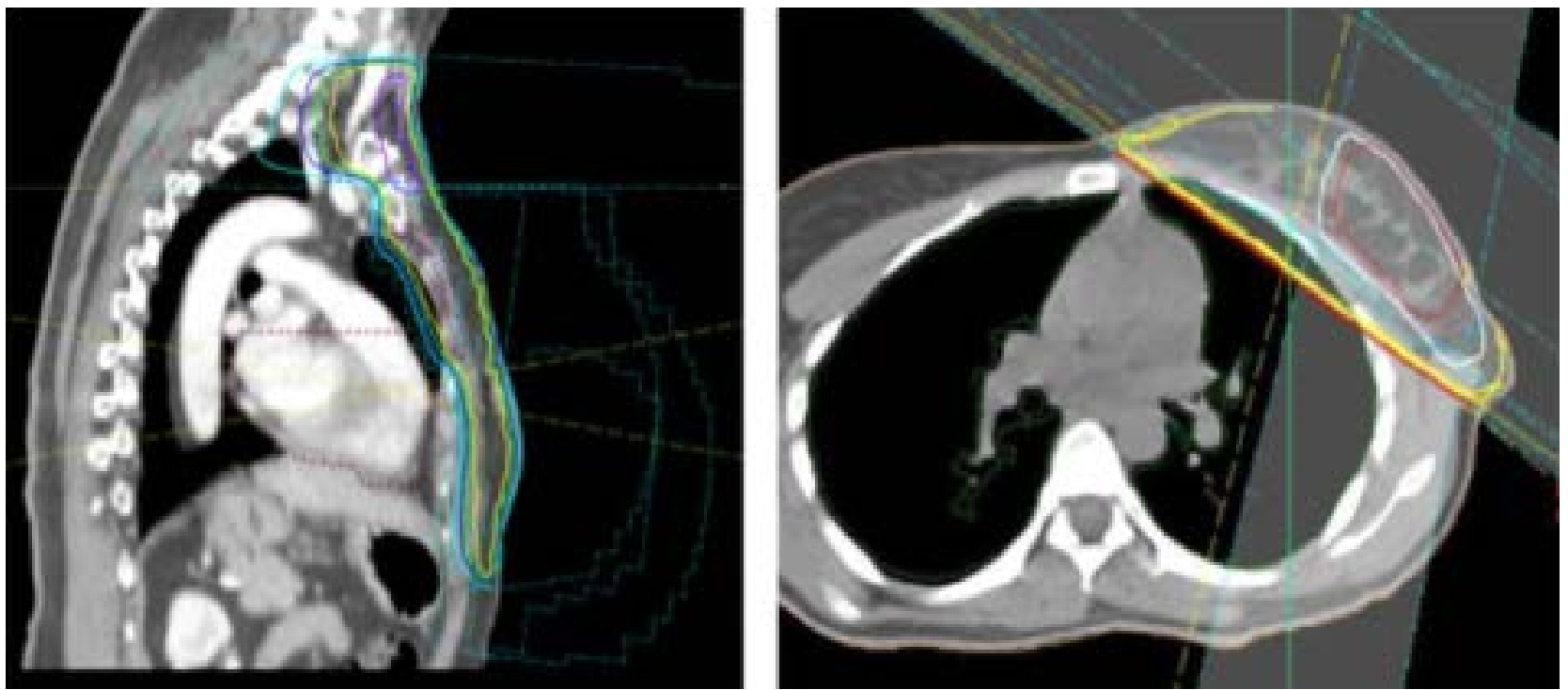

3D Technique 
producing cosmetic results similar or better than the conventional profile ${ }^{7,8}$.

This study aims to assess the cosmetic satisfaction of patients diagnosed with breast cancer submitted to hypofractionated RT with IMRT technique (hIMRT), and its correlation with dosimetric data of the radiotherapy planning.

\section{PATIENTS AND METHODS}

This is a retrospective uni-institutional cohort study that assessed women with diagnosis of non-metastatic breast malignant neoplasia submitted to conservative treatment or radical mastectomy, whether or not followed by immediate reconstruction, provided that no prosthesis, and submitted to the adjuvant irradiation of breast or chest wall (which corresponds to the surgical bed after mastectomy), with or without inclusion of classical lymph node sites with the hIMRT technique. The patients were assessed between August 2007 and December 2014. All included patients shall be a minimum follow-up of one year to assess the cosmesis.

The adopted exclusion criteria were: patients who did not complete the proposed RT, the presence of other neoplasia, except for non-melanoma skin or in situ carcinoma of cervix uteri, as well as information on insufficient follow-up for analysis.

The cosmetic assessment was made by the Harvard/RTOG/NSABP 9 scale by simple questions and comparison with the non-treated side (Table 1), from

TABLE 1 - ASSESSMENT OF COSMESIS

\begin{tabular}{l|l} 
Characteristic & \% Patients \\
\hline Stage & 20.2 \\
\hline O & 63.2 \\
\hline IA & 0.6 \\
\hline IB & 12.3 \\
\hline IIA & 2.5 \\
\hline IIB & 1.2 \\
\hline
\end{tabular}

\begin{tabular}{l|l}
\hline Histological Grade & \\
\hline Invasive ductal carcinoma & 72.1 \\
\hline Others & 27.9 \\
\hline
\end{tabular}

\begin{tabular}{l|l}
\hline Histological grade & \\
\hline I & 20.6 \\
\hline II & 35.3 \\
\hline III & 17.6 \\
\hline NA & 26.5 \\
\hline
\end{tabular}

one year after treatment. The data were collected by researches by review of records, phone interview, and satisfaction questionnaire.

Demographic data and aspects involved in the tumor were collected, such as histological type, staging, surgical extension, presence and type of breast reconstruction and additional treatments. In addition, dosimetric data was also collected: prescribed dose, volume of breast / chest wall (Clinic Target Volume, CTV), volumes that received 95\% (V95\%) and 107\% (V107\%) of the prescribed dose corresponding respectively to the coverage of target volume and volume of "hot spots", that is, it is assessed the homogeneity for distribution of dose. The planning system used was Oncentra Masterplan (Nucletron) ${ }^{\circledR}$.

The descriptive analysis was carried out by calculating the frequencies, mean and standard deviation (dp) or median and interquartile range (IQR). The assessment of association between cosmetic satisfaction and dosimetric data was carried out when using Kruskal-Wallis test. It was admitted the level of statistical significance $p<0.05$. The statistical analysis was carried out using the Stata ${ }^{\mathrm{TM}}$ program (version 11.2).

\section{RESULTS}

170 patients with a median age of 65.8 years (31 to 95 years, $d p=3$ years) were included. Among them, the majority (63.2\%) presented neoplasias in IA stage, $33(20.2 \%)$ in 0 stage and the other IB to III. The more frequent histological type was the invasive carcinoma with a special type (72.1\%). Thirty-four (20\%) patients carried out adjuvant chemotherapy and 135 (79.4\%) were submitted to anti-hormone therapy. One hundred and nine (64\%) patients were submitted to the conservative surgery and 61 (36\%) to modified radical mastectomy (Table 2).

The adopted hypofractionated profile was 40.05 Gy in 15 fractions to $43.5 \%$ of patients and $42.4 \mathrm{~Gy}$ in 16 fractions in $56.5 \%$ of cases assessed. Twelve patients $(7.0 \%)$ received irradiation of lymph node drainages and $28(16.3 \%)$ received a booster dose in the operative bed with a dose of $10 \mathrm{~Gy}$ in five fractions.

The volume of breasts treated ranged from 169 to $2.103 \mathrm{ml}$ (median = $702 \mathrm{ml}$; IQR: 535 to $914 \mathrm{ml}$ ), in which in $20 \%$, the volume was higher than 1.000 $\mathrm{ml}$ (Chart 1). Median V95\% was 86.7\% (54.6\%-96,6\%; IQR: $80.0 \%$ to $90.6 \%)$; eight (5.7\%) patients had V95\% 
TABLE 2 - PATIENTS CHARACTERISTICS

\begin{tabular}{|c|c|}
\hline \multicolumn{2}{|l|}{ Nuclear Grade } \\
\hline 1 & 14.1 \\
\hline$\|$ & 45.3 \\
\hline III & 24.7 \\
\hline NA & 15.9 \\
\hline \multicolumn{2}{|l|}{ Adjuvant Chemotherapy } \\
\hline Yes & 20 \\
\hline No & 80 \\
\hline \multicolumn{2}{|l|}{ Anti-Hormonal Treatment } \\
\hline Yes & 79.4 \\
\hline No & 20.6 \\
\hline \multicolumn{2}{|l|}{ Surgery } \\
\hline Conservative & 64 \\
\hline Radical mastectomy & 36 \\
\hline Reconstruction (without implants) & 15.9 \\
\hline \multicolumn{2}{|l|}{ hIMRT scheme } \\
\hline 15 fractions of 2.67Gy (40.05Gy) & 43.5 \\
\hline 16 fractions of 2.65Gy (42.40Gy) & 56.5 \\
\hline \multicolumn{2}{|l|}{ RT of LM drainage } \\
\hline Yes & 7 \\
\hline No & 93 \\
\hline \multicolumn{2}{|l|}{ Boost use during surgery } \\
\hline Yes & 16.3 \\
\hline No & 83.7 \\
\hline \multicolumn{2}{|l|}{ Cosmetic Assessment } \\
\hline Excellent & 74.4 \\
\hline Good & 24.1 \\
\hline Regular & 1.5 \\
\hline Bad & 0 \\
\hline
\end{tabular}

Excellent: Little or no difference in size, symmetry or shape Good: Slight asymmetry in size or shape

Regular: Obvious differences in size and/or shape

Bad: Marked change in appearance, involving more than 14 of the breast higher than 95\%. Median V107\% was 0\% (0\%-16.3\%; IQR: $0.0 \%$ to $0.3 \%$ and 13$)$; $9.3 \%$ patients had V107\% higher than $2 \% .133$ patients $(78.2 \%)$ responded to the questionnaire of cosmetic assessment. Among them, 99 (74.4\%) considered cosmetic results excellent, 32 (24.1\%) considered good, and two $(1,5 \%)$ considered reasonable (Table 2). Significant associations between cosmetic assessment and the breast volume were not found $(\mathrm{p}=0.875)$, V95\% $(\mathrm{p}=0.294)$ and $\mathrm{V} 107 \%$ $(\mathrm{p}=0.301)$.

\section{DISCUSSION}

Two decades ago, the first studies were designed, suggesting a hypofractionated treatment profile. It was sought an optimization of the dose-time relation to keep a maximum tumor response with rates of acceptable toxicity. Moreover, a shorter treatment profile would offer an advantage of a more efficient and productive use of the funds from RT department ${ }^{10}$.

The safety and efficacy, besides better cosmetic results compared to the conventional treatment, were shown in four randomized trials, involving 5.685 patients treated with hypofractionated profile ${ }^{11}$.

The Canadian study randomized 1.234 women among the doses of 42.5 Gy in 16 fractions or 50 Gy in 25 fractions. After a median follow-up of 69 months, there was no difference in relation to the free survival of local relapse and global survivals and 
free disease, with $77 \%$ of excellent or good cosmetic results in both arms ${ }^{12,13}$.

The Britain clinical trials Standardization of Breast Radiotherapy Trial, divided into (Start) A and $\mathrm{B}$, sought to define the ideal fractionation, finding results similar to the prior studies ${ }^{14}$. With a mean follow-up of five years, Start A included 2.236 operated patients with breast neoplasia (T1-T3, NO-N1), without immediate reconstruction. The patients were treated with 50 Gy in 25 fractions, 41.6 Gy in 13 fractions or $39 \mathrm{~Gy}$ in 13 fractions. In the results, the local failure was similar to the groups of $50 \mathrm{~Gy}$ and 41.6 Gy, showing an equivalence among the profiles. Start B assessed 2.215 patients treated with $50 \mathrm{~Gy}$ in 25 fractions and $40 \mathrm{~Gy}$ in 15 fractions. After a mean follow-up of six years, the local failure was similar in both groups. Moreover, the dose of $40 \mathrm{~Gy}$ offered results of the local and esthetic control as good as the profile of $50 \mathrm{~Gy}^{15}$.

When the first works of hypofractionation started, the concern about increasing the breast fibrosis and the worsening of cosmetic results increased, especially because of patients with voluminous breasts, there was a greater trend to a worst cosmetic result already showed in the results of works with conventional fractionation. In this way, many of these studies excluded women with voluminous breasts - in the Canadian studies, the patients were simply excluded if they had the distance between mean line and mean axillary line, measured in the breast center higher than $25 \mathrm{~cm}$ - and the trials that included these patients did not provide clear information about the impact on breast volume related to the toxicity and cosmesis, especially by the fact of using conventional radiotherapy ${ }^{16}$.

In the Canadian trials and Start, the toxicities were not worse when compared with patients who received the standard fractionation up to now (50 Gy in 25 daily fractions), in view of the study used as a radiobiological substrate for the equivalence of different treatments, the linear-quadratic mode ${ }^{17}$. Even though, the selection criteria of patients in these studies involved patients who did not receive prior chemotherapy, and in which there was no indication of irradiation of lymph nodes drainage nor immediate plastic reconstruction or voluminous breasts $^{18}$. The latest works published tried to assess the relation between cosmesis and dosimetry of the planning of these patients, who were submitted to breast hypofractionated RT because, besides radiobiological implications, it is important to consider the practical advantages of hypofractionation, such as its convenience in terms of costs both for patients and health service, and also patient's compliance to the treatment ${ }^{19}$.

It is known the importance of the correlation between toxicity and cosmetic results with patients' characteristics (age, comorbidities, body mass index) and medical treatments (neoadjuvant / adjuvant chemotherapy, hormonal deprivation, other concomitant drugs). Therefore, besides these factors being assessed, the impact of the CTV volume must be analyzed (representing the breast volume) and dosimetric data, especially focused on maximum dose and homogeneity of the planning (absolute volumes of breast tissues exposed to $\geq 107 \%$ of the dose prescribed). In this way, patients with postoperative complications or voluminous breasts for which a maximum dose $<107 \%$ is not reachable, or patients with implants for the increase or breast reconstruction would have an increased risk of late fibrosis or cosmetic deterioration after $\mathrm{RT}^{20}$.

Recently, a Chinese clinic study ${ }^{21}$, published only in a summary format, studied over 800 patients with post-mastectomy breast cancer and showed benefits of hypofractionated RT in the advanced disease with 43.5 Gy delivered over three weeks. After a five-year follow-up, the rates of tumor recurrence were not lower than standard RT with conventional fractionation. The rates of locoregional recurrence were $8.3 \%$ for hypofractionated RT and $8.1 \%$ in the standard treatment (HR=1.10, IC 95\%:0.67-1.83), with difference of $0.2 \%$ (IC $95 \%=-4.1$ to 4.5 ). The rates of free survival of disease were from $74.6 \%$ to hypofractionation arm and $70.7 \%$ for the standard treatment arm (HR $=0.88$, IC 95\%:0.67-1.16). The rates of global survival (GS) in five years were $83.2 \%$ after hypofractionation and $85.6 \%$ with standard treatment (HR=1.13, IC 95\%:0.78-1.62). In addition, fewer side effects were evidenced in patients of hypofractionation, indicating that hypofractionated RT after mastectomy is a safe and efficient option for the locally advanced disease ${ }^{21}$.

The guidelines of American Society of Therapeutic Radiology and Oncology (Astro), initially located in 2010, recommended the breast hypofractionation for patients in initial stages, age above 50 years, treated with conservation surgery, without chemotherapy or indication of lymph nodes irradiation, and with dosimetric parameters minimally acceptable, according to the techniques of conventional treatment ${ }^{22}$. These recommendations were based on the consensus of an 
expert panel, and not in formal contraindication. In this year of $2018^{23}$, the same society joined again and the panel updated the recommendations to a wider group of situations, such as the inclusion of systemic treatments, patients with advanced stages and without definitive age.

The breast volume as a relevant fact related to the skin toxicity is a contradictory topic in the pertinent literature. Many authors reported a close correlation between the breast size and intensity of acute effects ${ }^{24}$. It is up to us a questioning in relation to the criteria used for the definition of voluminous breast. Vicini et al. verified that patients with breast volume $>1.600 \mathrm{~cm}^{3}$ presented higher acute toxicity in the $\operatorname{skin}^{25}$. On the other hand, Harsolia et al. did not show level 3 acute toxicity with breast volume $<975$ $\mathrm{cm}^{326}$. An interesting note of Moody et al. was the evidence of the relation between the breast size and cosmesis associated with distributions of dose in its planning, finding a significant correlation between the breast size and the non-homogeneity of dose ${ }^{27}$.

This could explain the cosmetic changes in the appearance of the voluminous breasts, once great volumes are frequently associated with the non- homogeneity of the dose and maximum doses higher than $107 \%$ of the prescribed dose ${ }^{20}$. In addition to the acute toxicity, a higher breast volume may be correlated to an increased risk of late effects ${ }^{28}$. In this sense, IMRT could ensure higher homogeneity in the planning with great breast volumes. Many works that used hIMRT and allowed any breast sizes found lack of acute toxicity in the skin and presented dose of homogeneity lower than $7 \%^{29}$, data also showed in our study, with lack of significant correlation between the cosmesis and the breast volume, most likely in terms of homogenous terms with median V107\% of 0\% (0\%-16.3\%; IQR: $0.0 \%$ to $0.3 \%$ and 13$)$.

This study showed that breast volume did not have a correlation with prejudice to the cosmesis in the patients assessed, probably due to the benefit obtained with intensity-modulated planning. These findings allowed us to think about using hIMRT could expand the indications of hypofractionated RT for patients with voluminous breasts.

The more common changes in the appearance of the breast after RT are retraction, edema, and telangiectasia. These effects, in long-term, damage the cosmesis and are the results of the breast atrophy, and fibrosis. There are specific responses of fibrosis to the irradiation that may increase the proliferation of these cells and change and reabsorption of collagen ${ }^{30}$.

The late adverse effects usually show up after a mean follow-up ranging from five to ten years. The great critics to be carried out is if the cosmetic changes, in relation to the fractionation presented when was made the notes, are representing those that will develop over the patients' lives ${ }^{31}$.

Curran et al. showed in their studies that the cosmesis after breast hypofractionated RT was the worst in the patients followed by five years more ${ }^{32}$. In contrast, an English study did not show a significant difference in toxicity after RT between five and ten years of assessment ${ }^{33}$. Based on these considerations and uncertainties, currently, we cannot consider the follow-up as a factor that restricts the interpretation of the hypofractionated studies ${ }^{34}$.

It is important to highlight, as a counterpoint to the study, the times of different follow-up, once it is about a retrospective cohort. Many patients did not complete the estimating period from five to ten years of follow-up for the appearance of adverse effects, despite the initially established objective has been defined with at least one-year follow-up.

In addition, another point of difficult interpretation would be to know if the dissatisfaction in relation to the cosmesis happened after surgery or after radiotherapy since the patients were not assessed soon after the surgical procedure and the criteria were the comparison with contralateral breast. Moreover, it is currently hard to think about in patients with breast cancer treated with conservative surgery without adjuvant irradiation.

Despite these variables, $98.5 \%$ of patients considered the cosmetic results from good to excellent, with the lack of significant correlation between cosmesis and breast volume. This result highlights the importance and the potential impact of the lack of homogeneity, areas of dose $>107 \%$, of a planning with short fractionation.

Offering a shorter treatment is more convenient and preferred for patients when compared to the treatment from five to seven weeks, and was associated with quicker recovery. However, the hypofractionated breast treatment had its use limited due to the fear that it might increase fibrosis and worsen cosmetic results. The fact of this work is consistent with great randomized clinical trials support the indication as for the new standard since initially criteria should be respected as homogeneity and lack of reconstruction surgery with a prosthesis. 


\section{CONCLUSION}

The cosmetic results of the hIMRT for patients with breast cancer showed to be consistent with what is noted in the current literature, which is favorable to the use of hIMRT. The lack of correlation of the results with dosimetric data suggests that
hIMRT may minimize the heterogeneity of the dose and ensure this benefit even in voluminous breasts.

Prospective studies and with longer time of follow-up will be necessary to support the findings of this study.

\section{RESUMO}

OBJETIVO: Avaliar a satisfação cosmética de pacientes diagnosticadas com câncer de mama submetidas à radioterapia hipofracionada com técnica IMRT (hIMRT) e sua correlação com dados dosimétricos do planejamento radioterápico.

MATERIAIS E MÉTODOS: Estudo de coorte retrospectivo que avaliou mulheres com diagnóstico de neoplasia maligna de mama submetidas a tratamento conservador ou mastectomia radical e tratadas com hIMRT. No período de agosto de 2007 a dezembro de 2014 , em uma instituição filantrópica/particular, foram selecionados 170 prontuários. A avaliação cosmética foi feita por meio da escala de Harvard/RTOG/NSABP com um intervalo mínimo de um ano após o tratamento. Dados dosimétricos coletados foram: volume da mama/plastrão, volume que recebeu 95\% (V95\%) e 107\% (V107\%) da dose prescrita.

RESULTADOS: O volume das mamas tratadas variou de 169 a $2.103 \mathrm{ml}$ (mediana = 702; IQR: 535 a $914 \mathrm{ml}$ ). O V95\% mediano foi 86,7\% (54,6-96,6\%; IQR: 80,0\% a 90,6\%); oito (5,7\%) pacientes tiveram o V95\% superior a 95\%. O V107\% mediano foi 0\% (0\%-16,3\%; IQR: 0,0\% a 0,3\% e 13); 9,3\% pacientes tiveram o V107\% superior a 2\%. Cento e trinta e três (78,2\%) pacientes responderam à avaliação cosmética: 99 (74,4\%) consideraram o resultado cosmético excelente. Não foram encontradas associações significativas entre a avaliação cosmética e o volume da mama ( $p=0,875)$, V95\% ( $p=0,294)$ e V107\% ( $p=0,301)$.

CONCLUSÕES: Os resultados cosméticos mostraram-se favoráveis com o uso de hIMRT, e a ausência de correlação com os dados dosimétricos usuais ilustra a capacidade do hIMRT em minimizar a heterogeneidade da dose neste desfecho, mesmo em mamas volumosas.

PALAVRAS-CHAVE: Hipofracionamento. Neoplasia de mama. Radioterapia.

\section{REFERENCES}

1. M. Clarke, R. Collins, S. DarbyThe Early Breast Cancer Trialists Collaborative Group. Effects of radiotherapy and of differences in the extent of surgery for early breast cancer on local recurrence and 15-year survival: An overview of the randomised trials. Lancet, 366 (2005), pp. 2087-2106.

2. Gersem WD, Claus F, Wagter CD, et al. Leaf position optimization for step- and-shoot IMRT. Int | Radiat Oncol Biol Phys 2001; 51:1371-88.

3. Taylor C, et al. Estimating the Risks of Breast Cancer Radiotherapy: Evidence From Modern Radiation Doses to the Lungs and Heart and From Previous Randomized Trials. Journal of Clinical Oncology. March, 2017.

4. Mukesh B.et al. Randomized Controlled Trial of Intensity-Modulated Radiotherapy for Early Breast Cancer: 5-Year Results Confirm Superior Overall Cosmesis. JCO. Vol 31, N 36, Dec 2013.

5. Coles CE, Moody AM, Wilson CB, Burnet NG. Reduction of radiotherapyinduced late complications in early breast. Clin Oncol. 2005 17(2):98-110.

6. E.M. Donovan, U. Johnson, G. Shentall, P.M. Evans, A.J. Neal, |.R. Yarnold Evaluation of compensation in breast radiotherapy: a planning study using multiple static fields. Int J Radiat Oncol Biol Phys, 46 (2000), pp. 671-679.

7. Donovan E, Bleakley N, Denholm E, et al. Randomised trial of standard $2 \mathrm{D}$ radiotherapy ( $R T$ ) versus intensity modulated radiotherapy (IMRT) in patients prescribed breast radiotherapy. Radiother Oncol 2007;82:254-64.

8. Holloway C, Panet-Raymond V, Olivotto IA. Hypofractionation should be the new 'standard' for radiation therapy after breast conserving surgery. Breast. 2010;19:163-167.

9. National Surgical Adjuvant Breast and Bowel Project: NSABP Protocol B-39 Form COS

10. Awwad HK. Dose-Time-Volume relationships in nor- mal tissue to radiation. In Radiation Oncology: Ra- diobiological and Physiological Prespective. Kluwer Academic, Dordecht/ Boston/ London. 1990, 129- 187.

11. Owen JR, Ashton A, Bliss JM, et al. Effect of radiotherapy fraction size on tumour control in patients with early-stage breast cancer after local tumour excision: long-term results of a randomised trial. Lancet Oncol. 2006;7:467- 471 .
12. Whelan T, MacKenzie R, Julian J, Levine M, Shelley W, Grimard L, Lada B, Lukka H, Perera F, Fyles A, Laukkanen E, Gulavita S, Benk V, Szechtman B.Randomized trial of breast irradiation schedules after lumpectomy for women with lymph node-negative breast cancer. J Natl Cancer Inst. 2002 Aug 7;94(15):1143-50

13. Whelan TJ, Pignol JP, Levine MN, Julian JA, MacKenzie R, Parpia S, Shelley W, Grimard L, Bowen J, Lukka H, Perera F, Fyles A, Schneider K, Gulavita $\mathrm{S}$, Freeman C. Long-term results of hypofractionated radiation therapy for breast cancer. N Engl J Med. 2010 Feb 11;362(6):513-20.

14. The START Trialists' Group.The UK Standardisation of Breast Radiotherapy (START) Trial A of radiotherapy hypofractionation for treatment of early breast cancer: a randomised trial. Lancet Oncol 2008; published online March 19. DOI:10.1016/S1470-2045(08)70077-9.

15. The START Trialists' Group. The UK Standardisation of Breast Radiotherapy (START) Trial B of radiotherapy hypofractionation for treatment of early breast cancer: a randomised trial. Lancet 2008; published online March 19. DOI:10.1016/S0140-6736(08)60348-7.

16. Taher AN, El-Baradie MM, Essa H, Zaki O, Ezzat S: Hypofractionation versus conventional fractionation radiotherapy after conservative treatment of breast cancer: early skin reactions and cosmetic results. J Egypt Natl Canc Inst 2004, 16:178-187.

17. Bentzen SM. Steepness of the radiation dose-response curve for doseper-fraction escalation keeping the number of fractions fixed. Acta Oncol. 2005; $44: 825-828$

18. Haviland IS, Owen IR, Dewar IA START Trialists' Group, et al. The UK Standardisation of breast radiotherapy (START) trials of radiotherapy hypofractionation for treatment of early breast cancer: 10- year follow-up results of two randomised controlled trials. Lancet Oncol. 2013;14:10861094.

19. Cox JD, Stetz J, Pajak TF: Toxicity criteria of the Radiation Therapy Oncology Group (RTOG) and the European Organization for Research and Treatment of Cancer (EORTC). Int | Radiat Oncol Biol Phys 1995, 31:13411346. 
20. Rubin P, Constine LS: (RTOG Late Effects Working Group). Overview: late effects of normal tissues (LENT) scoring system. Int J Radiat Oncol Biol Phys 1995, 31:1041-1042.

21. Sun, G.Y. et al. Hypofractionated Radiation Therapy After Mastectomy for the Treatment of High-Risk Breast Cancer: 5-Year Follow-Up Result of a Randomized Trial. International Journal of Radiation Oncology • Biology • Physics, Volume 99, Issue 2, S3 - S4.

22. BD Smith, SM Bentzen, CR Correa, et al.Fractionation for whole breast irradiation: An American Society for Radiation Oncology (ASTRO) evidence- based guideline Int J Radiat Oncol Biol Phys, 81 (2011), pp. 5968.

23. Smith BD, Bellon JR, Blitzblau R, et al. Radiation therapy for the whole breast: Executive summary of an American Society for Radiation Oncology (ASTRO) evidence-based guideline. Pract Radiat Oncol 2018.

24. Deantonio L, Gambaro G, Beldi D, Masini L, Tunesi S, Magnani C, Krengl $M$ : Hypofractionated radiotherapy after conservative surgery for breast cancer: analysis of acute and late toxicity. Radiat Oncol 2010, 5:112.

25. Vicini FA, Sharpe M, Kestin L, Martinez A, Mitchell CK, Wallace MF, Matter R, Wong |: Optimizing breast cancer treatment efficacy with intensitymodulated radiotherapy. Int J Radiat Oncol Biol Phys 2002, 54(5):13361344

26. Harsolia, H. et al. Intensity-Modulated Radiotherapy results in significant decrease in clinical toxicities compared with conventional wedge-based breast radiotherapy. J. Radiation Oncology. Volume 68, Number 5, 2007.

27. Moody AM, Mayles WP, Bliss JM, Owen JR, Regan J, Broad B, et al. The influence of breast size on late radiation effects and association with radiotherapy dose inhomogeneity. Radiother Oncol. 1994, 33: 106-112.

28. Plataniotis GA, Dale RG: FIPEM., FRCR. Biologically effective dose- response relationship for breast cancer treated by conservative surgery and postoperative radiotherapy. Int | Radiat Oncol Biol Phys 2009, 75:512-517.

29. Freedman GM, Anderson PR, Goldstein LI, Ma CM, Li I, Swaby RF, Litwin S, Watkins-Bruner D, Sigurdson ER, Morrow M: Four-week course of radiation for breast cancer using hypofractionated intensity modulated radiation therapy with an incorporated boost. Int I Radiat Oncol Biol Phys 2007, 68(2):347-353.

30. Archambeau IO, Pezner R, Wasserman T. Pathophysiology of irradiated skin and breast. Int J Radiat Oncol Biol Phys. 1995, 31: 1171-1185.

31. Yarnold J, Bentzen SM, Coles C, Haviland J: Hypofractionated wholebreast radiotherapy for women with early breast cancer: myths and realities. Int | Radiat Oncol Biol Phys 2011, 79:1-9.

32. Curran D, van Dongen IP, Aaronson NK, Kiebert G, Fentiman IS, Mignolet F, Bartelink $\mathrm{H}$ : Quality of life of early-stage breast cancer patients treated with radical mastectomy or breast-conserving procedures: results of EORTC Trial 10801. Eur | Cancer 1998, 34:307-314.

33. Yarnold J, Ashton A, Bliss I, Homewood J, Harper C, Hanson I, Haviland I, Bentzen S, Owen R: Fractionation sensitivity and dose response of late adverse effects in the breast after radiotherapy for early breast cancer: long-term results of a randomised trial. Radiother Oncol 2005, 75:9-17.

34. Bartelink $H$, Arriagada R: Hypofractionation in radiotherapy for breast cancer. Lancet 2008, 371:1050-1052. 